\title{
Preferential expression of PAPPA in human preadipocytes from omental fat
}

\author{
Caroline Davidge-Pitts ${ }^{1}$, Carlos J Escande ${ }^{2}$ and Cheryl A Conover ${ }^{1}$ \\ ${ }^{1}$ Endocrine Research Unit, Division of Endocrinology and ${ }^{2}$ Kogod Center on Aging, Mayo Clinic, 200 First Street SW, \\ Rochester, Minnesota 55905, USA
}

Correspondence should be addressed to C A Conover Email Conover.Cheryl@mayo.edu

\begin{abstract}
Fat distribution differs between individuals, and those with visceral fat predominance develop metabolic profiles that increase the risk of adverse cardiovascular events. This is due, in part, to the proinflammatory state associated with visceral obesity as well as depot-specific adipogenesis. The IGF system is important in adipose tissue development and metabolic function. Pregnancy-associated plasma protein A (PAPPA) is a novel zinc metalloproteinase that regulates local IGF availability. The first aim of this study was to characterize PAPPA mRNA and protein expression in primary cultures of human preadipocytes isolated from omental, mesenteric, and subcutaneous depots. PAPPA expression was significantly increased in omental preadipocytes compared with mesenteric and subcutaneous preadipocytes. The second aim of this study was to investigate the factors regulating PAPPA expression, focusing on proinflammatory cytokines and resveratrol that have been shown to have negative and positive effects, respectively, on metabolism and diet-induced obesity. Treatment of cultured primary human preadipocytes with tumor necrosis factor $\alpha$ and interleukin $1 \beta$ led to significant increases in PAPPA expression. Activated pathways mediating cytokine-induced PAPPA expression include the nuclear factor $\kappa B$ pathway and the MAPK family, particularly c-Jun $\mathrm{NH}_{2}$-terminal kinase and p38 MAPK. Resveratrol, a polyphenolic compound with beneficial cardiometabolic effects, significantly downregulated PAPPA expression under basal and stimulated conditions. Effects of resveratrol on PAPPA appeared to be mediated through pathways independent of silent mating type information regulation 2 homolog 1 (SIRT1) and AMP kinase activation. Depot-specific PAPPA expression in human preadipocytes may contribute to a depot-specific function.
\end{abstract}
Key Words
- PAPPA
- adipose tissue
- resveratrol
- cytokines
- inflammation

Journal of Endocrinology (2014) 222, 87-97

\section{Introduction}

The prevalence of obesity is increasing, particularly in westernized countries, and is now considered an epidemic. Distribution of fat may differ between individuals, and metabolic functions of adipose tissue are inherently distinct between their fat depots (Caserta et al. 2001). This is due, in part, to regional variation of preadipocytes with respect to adipocyte development and metabolic function. Obesity is considered a low-grade proinflammatory state with increased circulating cytokines, chemokines, and growth factors (Lacasa et al. 2007). This adipose tissue inflammation leads to a higher likelihood of adverse metabolic profiles, including diabetes and atherosclerosis, particularly 
in subjects with visceral fat predominance (Coppack 2001, Tchkonia et al. 2010). Little is known about the regulatory factors leading to a depot-specific function.

Genome-wide expression profiles of primary preadipocytes from human fat depots identified pregnancyassociated plasma protein A (PAPPA) as one of the most distinctive genes expressed, with levels in preadipocytes from omental fat greatly exceeding those from subcutaneous fat (Tchkonia et al. 2007). PAPPA is a zinc metalloproteinase that enhances local insulin-like growth factor (IGF) action through cleavage of inhibitory proteins that bind IGFs with high affinity, thereby freeing the IGFs in the pericellular environment to bind and activate receptors (Conover 2012). Elevated PAPPA level has been implicated in aging and age-related disease, while Pappa knockout mice have a 30\% longer lifespan than WT mice, with resistance to atherosclerotic plaque development (Harrington et al. 2007, Conover et al. 2010, Boldt et al. 2013) and visceral fat accumulation on high-fat diet (Conover et al. 2013).

In this study, we follow up on the DNA microarray data and characterize PAPPA mRNA and protein expression in primary cultures of human preadipocytes from omental, mesenteric, and subcutaneous fat depots. Furthermore, we investigate the factors that regulate PAPPA expression in human preadipocytes and the underlying mechanisms for their regulation, including proinflammatory cytokines and resveratrol, the latter being a polyphenolic compound shown to have beneficial cardiometabolic effects.

\section{Materials and methods}

\section{Materials}

Tumor necrosis factor alpha (TNF $\alpha$ ) was purchased from Research Diagnostics, Inc. (Flanders, NJ, USA). Interleukin $1 \beta$ (IL1 $\beta)$, IL6, IL6 soluble receptor, and EX-527 were purchased from R\&D Systems (Minneapolis, MN, USA). Antibodies against total and phosphorylated ERK1/2, c-Jun $\mathrm{NH}_{2}$-terminal kinase (JNK), p38 MAPK, nuclear factor $\kappa \mathrm{B}(\mathrm{NF} \kappa \mathrm{B}$ ) (including inhibitory $\kappa \mathrm{B} \alpha$ and $\beta$ (I $\kappa \mathrm{B} \alpha$ and IкB $\beta)$ ), phospho-Hsp27, and IGFBP4 were purchased from Abcam (Cambridge, MA, USA). Antibodies against total and phosphorylated AKT were purchased from Novus Biologicals (Littleton, CO, USA). SB203580, SP600125, rolipram, and splitomycin were purchased from Enzo Life Sciences (Farmingdale, NY, USA). BAY11-7082 was purchased from Calbiochem (San Diego, CA, USA). Resveratrol was purchased from Sigma-Aldrich.
Reagents for SDS-PAGE, mini gels, and blocking buffer were purchased from Bio-Rad Laboratories and tissue culture supplements and fetal bovine serum were purchased from Life Technologies. A769662 was purchased from Santa Cruz Biotechnology.

\section{Cell culture}

Human adipose tissue was obtained under Mayo Clinic IRB-approved protocols. Human preadipocytes isolated from subcutaneous, mesenteric, and omental fat depots were cultured in alpha MEM containing 10\% fetal bovine serum, 100 units $/ \mathrm{ml}$ penicillin, and $100 \mathrm{mg} / \mathrm{ml}$ streptomycin as described previously (Tchkonia et al. 2002, 2007). Donor characteristics are summarized in Table 1. Cells of the third to ninth passage were used in experiments. Preliminary dose-response and time-course experiments were carried out to determine the effective concentrations and appropriate duration of treatments. For some studies, cells were pretreated for $60 \mathrm{~min}$ with resveratrol before the addition of cytokines. At the end of the incubation,

Table 1 Human preadipocytes: donor characteristics. Numbers in parentheses on the left indicate the number of donors for which information was available. Numbers for specific diseases and medications on the right indicate the number of donors. Some donors will have more than one

\begin{tabular}{lc}
\hline Gender (M/F) (15) & $3 / 12$ \\
Age (years) (15) & $41 \pm 2.5$ \\
BMI (kg/m²) (15) & $51 \pm 3.7$ \\
Concomitant diseases (9) & 2 \\
Diabetes & 3 \\
Degenerative joint disease & 3 \\
Obesity hypoventilation syndrome & 2 \\
Gastroesophageal reflux disease & 2 \\
Sleep apnea & \\
Others & \\
Medications & $2^{\mathrm{b}}$ \\
Diabetes & $5^{\mathrm{c}}$ \\
Heart/blood pressure & $5^{\mathrm{d}}$ \\
Heartburn & $4^{\mathrm{e}}$ \\
Depression & $3^{\mathrm{f}}$ \\
Inflammation/pain & \\
Others &
\end{tabular}

aOne each hypothyroidism, hyperlipidemia, asthma, hypertension, and recurrent sinus infection.

${ }^{b}$ Avandia, Metformin, and Prandin.

'Sotalol, Lasix, Digoxin, Avapro, Hydrochlorothiazide, Lovenox, Lipitor, Lopid, Verapamil, and Norvasc.

dPrilosec.

ePaxil, Zoloft, Celexa, Trazodone, Prozac, and Lorazepam.

fFlonase, Vioxx, Nasacort, Zyrtec, and Vicodin.

${ }^{9}$ One each Carbidopa/Levodopa, Unithroid, Ortho-Novum, and Intraconozole. 
conditioned media were collected and cells were harvested for RNA and stored at $-80^{\circ} \mathrm{C}$.

\section{Real-time PCR}

Upon harvest, the preadipocytes were immediately suspended in TRIzol (Life Technologies). Total RNA was then isolated, reverse transcribed with the SuperScript III First-Strand Synthesis System (Life Technologies), and evaluated by quantitative real-time PCR using the iCycler iQ5 Detection System with iQ SYBR Green PCR Master Mix (Bio-Rad). Amplification plots were analyzed with iQ5 Optical System Software version 2.1 (Bio-Rad). Primer sequences for specific detection and amplification of PAPPA as well as assay validations were described previously (Conover et al. 2006).

\section{Western blotting}

Following experimental treatments, cells were lysed, subjected to SDS-PAGE, and transferred onto PVDF membranes. Filters were blocked with $5 \%$ non-fat dry milk in Tris-buffered saline/0.1\% Tween 20 or blocking buffer (Bio-Rad) and probed with a primary antibody at the recommended dilution. After the reaction, secondary antibody was applied (fluorescent labeled where applicable (LI-COR, Lincoln, NE, USA)). Blots were visualized using enhanced chemiluminescence reagents and autoradiography or captured with LI-COR Odyssey Imagers.

\section{PAPPA ELISA}

Conditioned medium (CM) from human preadipocytes was collected, cellular debris was removed by centrifugation, and the supernatant was stored at $-80^{\circ} \mathrm{C}$ before assay. Protein was quantified using the Pierce BCA Protein assay kit (Thermo Scientific, Waltham, MA, USA). PAPPA protein in the CM was quantified by picoPAPP-A ELISA (generously provided by AnshLabs, Webster, TX, USA), a high-sensitivity assay designed to detect PAPPA levels as low as $100 \mathrm{pg} / \mathrm{ml}$ with observed $\mathrm{CV}$ values routinely $<5.0$. Some of the early experiments with conditioned media were carried out using the Ultra-sensitive PAPP-A ELISA kit kindly provided by Diagnostic Systems Laboratories, Inc. (Webster, TX, USA) as described previously (Boldt \& Conover 2011).

\section{Miscellaneous biochemistries}

TNF $\alpha$ and IL1 $\beta$ levels in CM were assayed by the Mayo Clinic Immunochemical Core Laboratory.

\section{Statistical analysis}

Results are expressed as mean \pm s.E.M. for the indicated number of experiments. The number of experiments noted in figure legends is based on primary cultured cells from different donors. We used ANOVA for pairwise comparisons and the Bonferroni correction for multiple comparisons. We used two-sample $t$-tests to compare two groups. Significance was set at $P<0.05$.

\section{Results}

\section{Depot-specific PAPPA expression}

PAPPA mRNA and protein expression were determined in the primary cultures of human preadipocytes collected from subcutaneous, mesenteric, and omental adipose tissue depots by real-time PCR and PAPPA ELISA respectively. As shown in Fig. 1A, PAPPA mRNA expression was
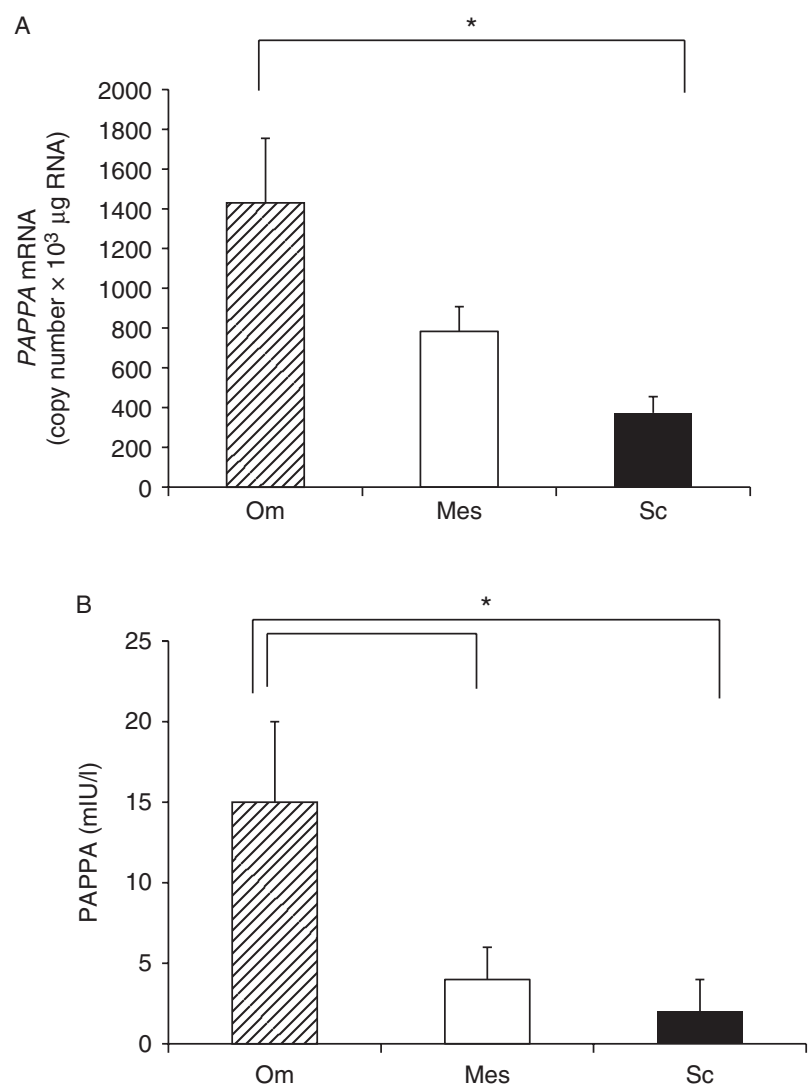

Figure 1

PAPPA expression in human preadipocytes. (A) PAPPA mRNA and (B) PAPPA protein expression in preadipocytes from omental (Om), mesenteric (Mes), and subcutaneous (Sc) depots were determined by real-time PCR and PAPPA ELISA, respectively, as described in the Materials and methods section. Results are expressed as mean \pm S.E.M., $n=6-10$. ${ }^{*} P<0.05$.

Published by Bioscientifica Ltd. 
significantly higher (fourfold) in omental preadipocytes compared with subcutaneous preadipocytes. Although abdominal in origin, mesenteric fat is distinct from omental fat with respect to cellular and gene expression properties. In our experiments, PAPPA mRNA expression in omental fat was twofold higher than that in mesenteric fat. Levels of PAPPA protein were also significantly higher in $\mathrm{CM}$ from omental preadipocytes compared with both mesenteric and subcutaneous preadipocytes (Fig. 1B). Although these primary cultures of preadipocytes came from severely obese donors (Table 1), PAPPA protein in extracts of fat depots from subjects with a BMI $<30 \mathrm{~kg} / \mathrm{m}^{2}$ showed the same significant difference (four- to sixfold) between omental and subcutaneous depots (data not shown). Furthermore, concomitant diseases or the variety of medications taken by the donors (Table 1) did not influence this differential expression. Thus, depot-specific PAPPA expression is highest in preadipocytes from human visceral fat.

\section{Regulation of PAPPA expression by cytokines}

The effects of proinflammatory cytokines, TNF $\alpha$, IL $1 \beta$, and IL6, on PAPPA expression were determined in subcutaneous, mesenteric, and omental preadipocytes. Cells were treated with both IL6 and the IL6 soluble receptor to provide more reliable activation of the IL6 signaling protein, gp130, in the preadipocytes (Franchimont et al. 1997, Resch et al. 2006). PAPPA mRNA levels increased in response to TNF $\alpha$ and IL1 $\beta$ after $6 \mathrm{~h}$ and remained increased for $24 \mathrm{~h}$ based on timecourse experiments (data not shown). The effects of these cytokines on PAPPA mRNA expression are shown in Fig. 2. $\mathrm{TNF} \alpha$ and IL1 $\beta$ led to a significant threefold increase in PAPPA mRNA expression in the omental and mesenteric preadipocytes with no significant increase observed in the subcutaneous preadipocytes. No significant effect was observed on PAPPA expression after treatment with IL6 and IL6 soluble receptor. PAPPA protein levels in CM were also increased by TNF $\alpha$ and IL1 $\beta$, with no effect after treatment with IL6 (data not shown).

To determine the intracellular pathways mediating TNF $\alpha$ and IL1 $\beta$ stimulation of PAPPA expression in human preadipocytes, we focused on those commonly associated with stress, apoptosis, and proliferation. These included MAPK family, phosphatidylinositol 3-kinase (PI3K), and NFאB pathways.

The MAPK family has three main subgroupings: Erk1/2, p38 kinase, and JNK. Western blot analyses were performed using antibodies specific for these pathways. Stimulation with TNF $\alpha$ and IL1 $\beta$ had little effect on Erk1/2

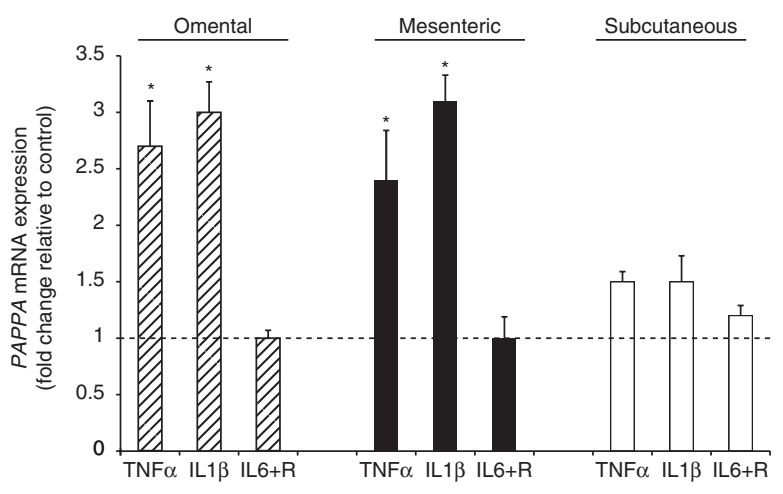

Figure 2

Effect of cytokines on PAPPA expression. Preadipocytes were stimulated with TNF $\alpha(1 \mathrm{nM})$, IL1 $\beta(1 \mathrm{nM})$, and IL6 $(50 \mathrm{ng} / \mathrm{ml})$ with soluble receptor $(100 \mathrm{ng} / \mathrm{ml})$ for $24 \mathrm{~h}$. Upon harvest, RNA was isolated from preadipocytes, reverse transcribed, and evaluated by quantitative real-time PCR. Results (mean \pm s.E.M., $n=3-4$ ) are expressed relative to control (represented by the dotted line). ${ }^{*} P<0.05$.

phosphorylation but induced p38 phosphorylation at 10 and 30 min with a decrease toward basal levels at 60 and $120 \mathrm{~min}$. JNK phosphorylation was induced 10 and 30 min after stimulation with IL1 $\beta$ but returned to baseline at $60 \mathrm{~min}$. IL1 $\beta$ appeared to be more effective than TNF $\alpha$ in activating the JNK pathway (Figs 3A and 4B).

Treatment of human preadipocytes with $\mathrm{TNF} \alpha$ and IL1 $\beta$ for $10,30,60$, or 120 min did not result in detectable AKT phosphorylation, a downstream substrate for PI3K. Reprobing with an antibody against total AKT indicated that the protein was present (data not shown).

$\mathrm{NF} \kappa \mathrm{B}$ is usually sequestered in the cytoplasm bound to

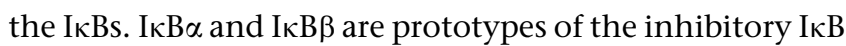
family. NFKB is activated through phosphorylation of the

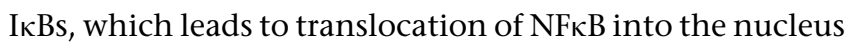
where the regulation of gene expression occurs (Resch et al. 2006). Western blotting after stimulation with TNF $\alpha$ and IL1 $\beta$ led to a rapid loss of IкB $\alpha$ within $10 \mathrm{~min}$, which returned to detectable levels by $60 \mathrm{~min}$. TNF $\alpha$ and IL1 $\beta$ had little or no effect on IкB $\beta$ (Fig. 3B).

Inhibitors of the NFKB (BAY11-7082), JNK (SP600125), and p38 (SB203580) pathways were evaluated by western blotting to establish effectiveness (Fig. 4). To determine which pathways mediated cytokine-stimulated PAPPA gene expression, real-time RT-PCR was carried out on RNA isolated from human preadipocytes treated with the inhibitors BAY11-7082, SB203580, and SP600125 and then stimulated with IL1 $\beta$ and TNF $\alpha$. BAY11-7082 (NFKB inhibitor) significantly inhibited IL1 $\beta$ - and TNF $\alpha$ stimulated PAPPA gene expression (Fig. 5A). SB203580

Published by Bioscientifica Ltd. 


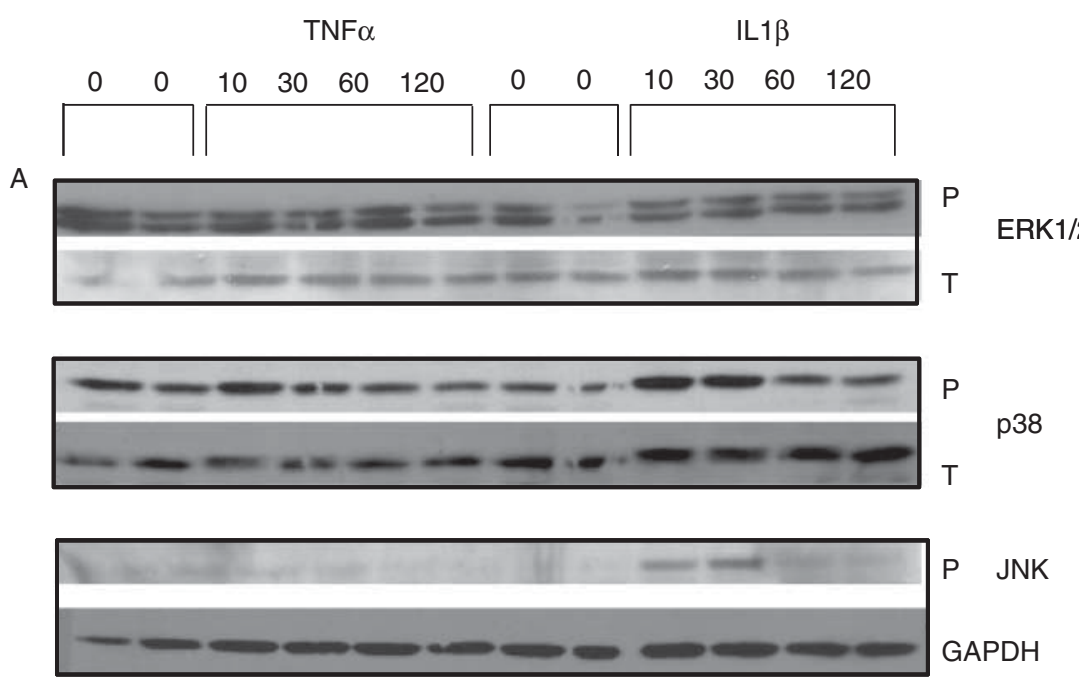

B

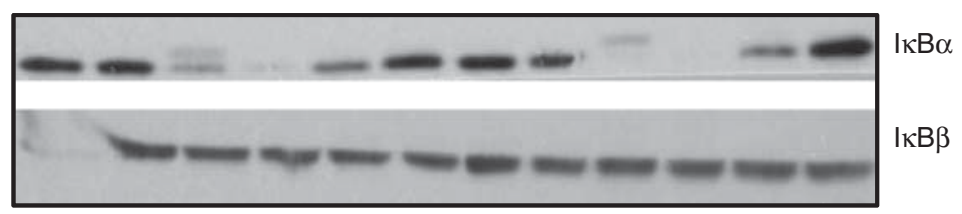

\section{Figure 3}

TNF $\alpha$ and IL $1 \beta$ regulation of (A) MAPK and (B) NFKB signaling. Human preadipocytes from omental fat were treated with TNF (1 nM) or IL1 $\beta$ $(1 \mathrm{nM})$ for the indicated times. Western blotting was performed for

(p38 inhibitor) showed similar inhibition, but did not reach statistical significance (Fig. 5B). SP600125 (JNK inhibitor) significantly inhibited IL1 $\beta$-induced, but not TNF $\alpha$-induced, PAPPA expression (Fig. 5C).

In summary, the intracellular pathways mediating PAPPA upregulation by IL1 $\beta$ and TNF $\alpha$ are commonly associated with stress, including $\mathrm{NF \kappa B}, \mathrm{p} 38$, and JNK, although IL1 $\beta$ and TNF $\alpha$ seem to have differing effects on activation of the JNK pathway in human preadipocytes.

\section{Regulation of PAPPA expression by resveratrol}

Resveratrol is found in multiple plant derivatives such as grapes and grape products (Baur et al. 2012). There has been much interest in resveratrol over the last decade, due to its potential protective metabolic effects. Pretreatment of human preadipocytes with resveratrol at a concentration of $50 \mu \mathrm{M}$ led to a significant reduction in both PAPPA mRNA and protein expression under basal conditions (Fig. 6A). The effect of resveratrol on PAPPA expression was observed in preadipocytes from all three depots. Resveratrol also markedly inhibited IL1 $\beta$ - and TNF $\alpha$-stimulated PAPPA mRNA expression (Fig. 6B). The effects of phosphorylated (P) Erk1/2, p38 and JNK, total (T) p38 and ERK1/2, and IкB $\alpha$ and $I \kappa B \beta$ as described in the Materials and methods section. GAPDH was used to quantify loading for P-JNK.

stimulating PAPPA expression in preadipocytes (IL1 $\beta$ treatment) and inhibiting PAPPA expression (resveratrol treatment) on PAPPA activity, i.e., IGFBP4 proteolysis, are shown in Fig. 7. IL1 $\beta$ increased IGFBP4 fragmentation and

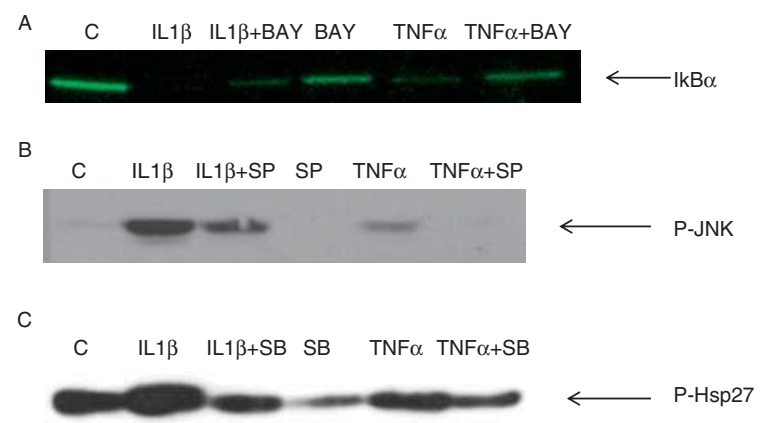

Figure 4

Efficacy of inhibitor concentrations. Human preadipocytes from omental fat were treated with BAY11-7082 $(5 \mu \mathrm{M})$, SP600125 $(20 \mu \mathrm{M})$ or SB203580 $(2.5 \mu \mathrm{M})$, and cytokines TNF $\alpha(1 \mathrm{nM})$ and IL1 $\beta(1 \mathrm{nM})$ for $6 \mathrm{~h}$ before cell lysis for western blotting. (A) Effect of BAY11-7082 on cytokine-induced NFKB activation ( $\mid \kappa B \alpha$ phosphorylation and degradation). (B) Effect of SP600125 on cytokine-induced JNK activation (phosphorylation of JNK). (C) Effect of SB203580 on cytokine-induced p38 kinase activation (phosphorylation of Hsp27). C, control.

Published by Bioscientifica Ltd. http://joe.endocrinology-journals.org DOI: 10.1530/JOE-13-0610
(C) 2014 Society for Endocrinology Printed in Great Britain 


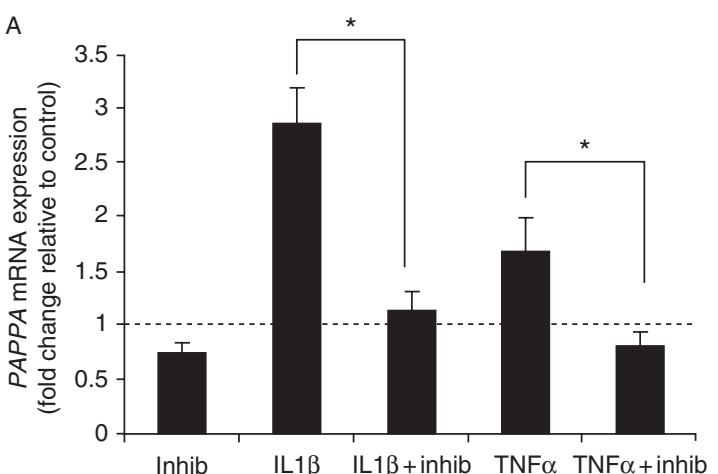

B
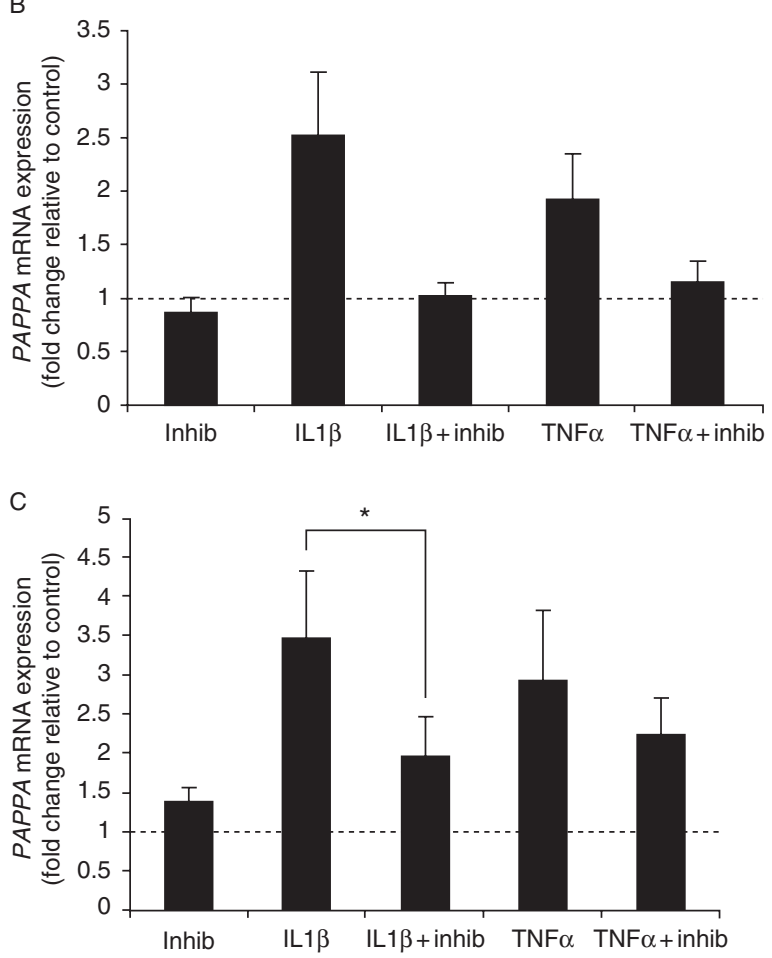

Figure 5

Effect of pathway inhibitors on PAPPA expression. Real-time PCR was carried out on RNA isolated from omental preadipocytes treated with (A) NFKB inhibitor BAY11-7082 (5 $\mu \mathrm{M})$ (B) p38 inhibitor SB203580 (2.5 $\mu \mathrm{M})$, and (C) JNK inhibitor SP600125 (20 $\mu \mathrm{M})$, and then stimulated with IL1 $\beta$ $(1 \mathrm{nM})$ and TNF $\alpha(1 \mathrm{nM})$ for $24 \mathrm{~h}$. Results (mean \pm s.E.M., $n=6)$ are expressed relative to control (represented by dotted line). ${ }^{*} P<0.05$. Inhib, inhibitor.

resveratrol inhibited the appearance of fragments. Addition of a neutralizing PAPPA antibody confirmed the specificity of PAPPA-mediated IGFBP4 proteolysis.

Resveratrol is thought to act through multiple pathways, but primarily through activation of silent mating type information regulation 2 homolog 1 (SIRT1), a mammalian sirtuin that is thought to extend lifespan in a variety of species (Howitz et al. 2003, Wood et al. 2004). Other resveratrol targets include the activation of AMP kinase (AMPK), part of a nutrient-sensing pathway, which may also activate SIRT1 (Park et al. 2012). To determine whether resveratrol exerts its effects on PAPPA expression through SIRT1, preadipocytes were treated with the SIRT1 inhibitor, EX-527, plus resveratrol. SIRT1 is a deacetylase enzyme with p53 as a native substrate. We confirmed acetylation of p53 in the presence of EX-527 by western blotting (Fig. 8A). Resveratrol effectively downregulated PAPPA mRNA expression in the presence of EX-527 (Fig. 8B). We confirmed our findings using two other SIRT1 inhibitors, splitomycin and nicotinamide (data not shown). To determine whether resveratrol exerts its effects on
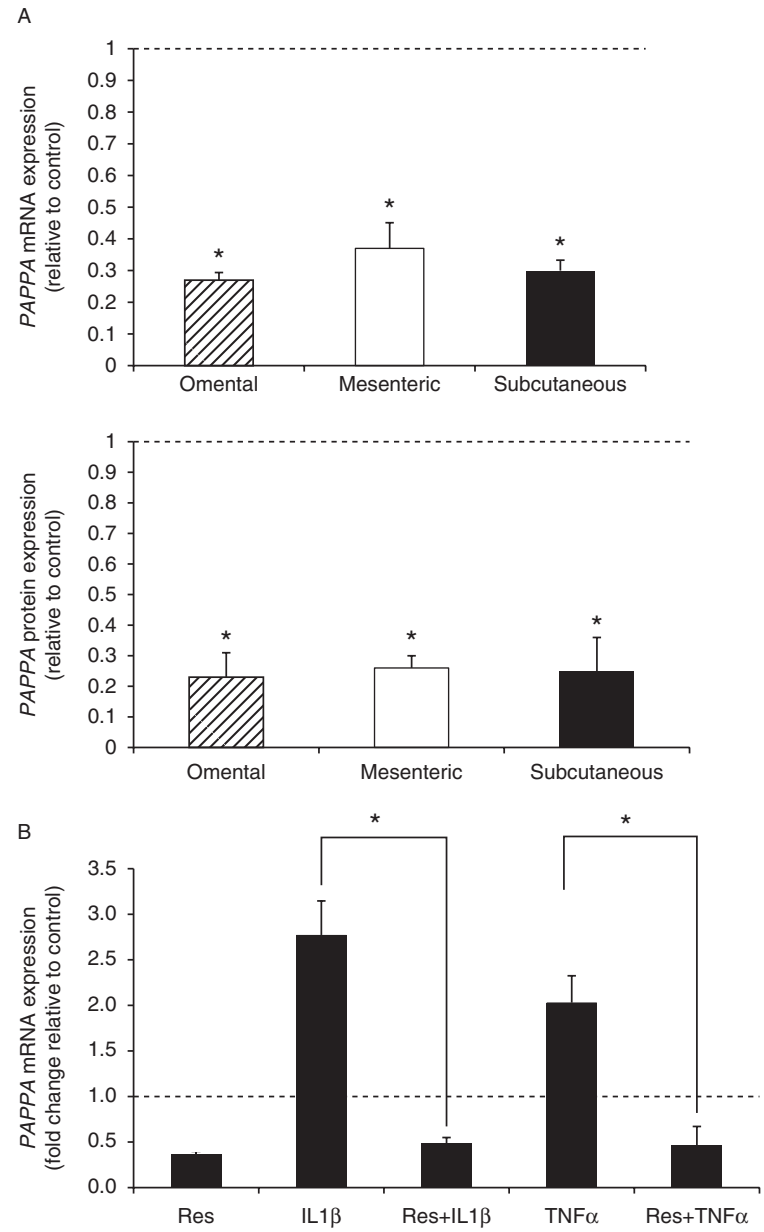

Figure 6

Effect of resveratrol on PAPPA expression. (A) Preadipocytes were treated with resveratrol (Res; $50 \mu \mathrm{M}$ ) for $24 \mathrm{~h}$. (B) Omental preadipocytes were treated with resveratrol $(50 \mu \mathrm{M})$ alone, resveratrol plus cytokines IL1 $\beta(1 \mathrm{nM})$ and TNF $\alpha(1 \mathrm{nM})$, and cytokines IL1 $\beta$ and TNF $\alpha$ alone for $24 \mathrm{~h}$. Preadipocytes were then harvested for real-time PCR. Results (mean \pm S.E.M., $n=3-10$ ) are expressed relative to control (represented by dotted line). ${ }^{*} P<0.05$. 


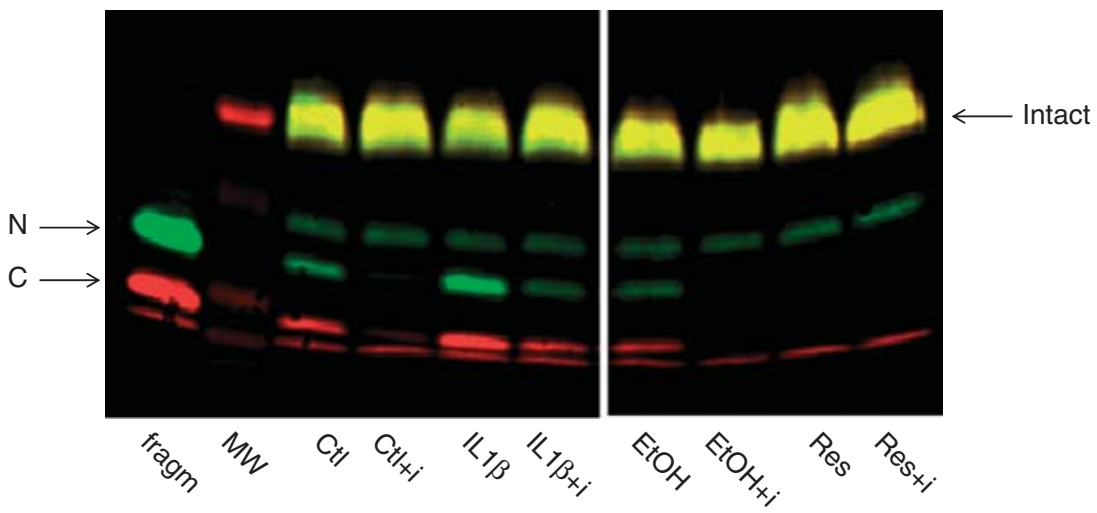

\section{Figure 7}

Effect of IL1 $\beta$ and resveratrol on PAPPA activity. Omental preadipocytes were incubated with IL1 $\beta$ ( $1 \mathrm{nM})$, resveratrol ( $50 \mu \mathrm{M})$, or appropriate vehicle for $24 \mathrm{~h}$. Conditioned medium was collected and incubated with IGFBP4 and IGF2 without or with a PAPPA inhibitory antibody (i). Arrows indicate intact and N- and C-terminal fragments of IGFBP4. frag, positive control for PAPPA-mediated IGFBP4 proteolysis; Res, resveratol.

PAPPA expression through AMPK, preadipocytes were treated with resveratrol or the AMPK activator, rolipram (Park et al. 2012). AMPK phosphorylation analyzed by western blotting was used to confirm the activity of rolipram before experiments (Fig. 8C). Treatment with rolipram did not reduce PAPPA mRNA or protein expression (Fig. 8D). We confirmed our findings using a second AMPK activator, A769662, with similar results (data not shown).

In summary, resveratrol leads to downregulation of PAPPA expression in human preadipocytes under both basal and cytokine-stimulated conditions. The effects of
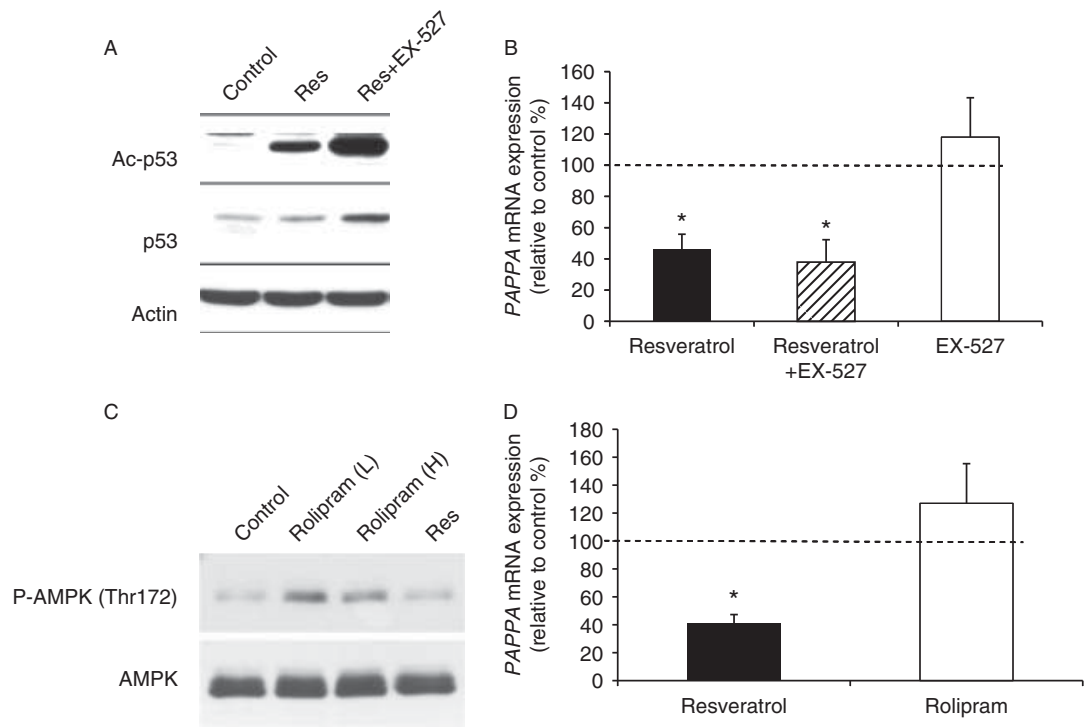

\section{Figure 8}

Effect of SIRT1 inhibition and AMPK activation on PAPPA expression. (A) Omental preadipocytes were treated with resveratrol (Res) $(50 \mu \mathrm{M})$ and EX-527 $(10 \mu \mathrm{M})$ for $24 \mathrm{~h}$. Western blotting was performed for $\mathrm{p} 53$ and acetylated $\mathrm{p53}$. (B) Omental preadipocytes were treated with resveratrol alone, resveratrol plus SIRT1 inhibitor EX-527 $(10 \mu \mathrm{M})$, and EX-527 alone for $24 \mathrm{~h}$. Preadipocytes were then harvested for real-time PCR. Results (mean \pm S.E.M., $n=3$ ) are expressed relative to control (represented by dotted line).
(C) Omental preadipocytes were treated with rolipram (25 (L) and $50(\mathrm{H})$ $\mu \mathrm{M})$ for $24 \mathrm{~h}$. Western blotting was performed for AMPK and phosphorylated AMPK (P-AMPK). (D) Omental preadipocytes were treated with resveratrol or the AMPK activator, rolipram $(25 \mu \mathrm{M})$, for $24 \mathrm{~h}$. Preadipocytes were then harvested for real-time PCR. Results (mean \pm s.E.M., $n=4$ ) are expressed relative to control (represented as dotted line). ${ }^{*} P<0.05$. http://joe.endocrinology-journals.org DOI: 10.1530/JOE-13-0610
(C) 2014 Society for Endocrinology Printed in Great Britain
Published by Bioscientifica Ltd 
resveratrol on PAPPA are not mediated through the AMPK or SIRT1 pathway.

\section{Discussion}

PAPPA is preferentially expressed in human preadipocytes from visceral fat depots compared with preadipocytes from subcutaneous depots

Obesity is commonly associated with health risks, particularly cardiovascular disease. Individuals may preferentially accumulate fat in specific anatomical fat depots including the upper-body subcutaneous fat depot, the lower-body fat depot (intramuscular fat, the subcutaneous leg fat, and the gluteal fat), and the intra-abdominal fat depot (mesenteric and omental fat, or visceral fat) (Tchkonia et al. 2010). Adipose tissue in these fat depots may behave differently. The typical 'pear' shape of fat distribution (peripheral fat distribution) may lead to fewer cardiovascular risk factors than the typical 'apple' shape of fat distribution (central fat accumulation). Omental fat accumulation, in particular, is associated with adverse metabolic risk profiles including diabetes, insulin resistance, dyslipidemia, and atherosclerosis with dysregulation of fatty acid storage and release. Although abdominal in origin, mesenteric fat is distinct from omental fat with respect to cellular and gene expression properties (Tchkonia et al. 2013). Our studies indicate that PAPPA is preferentially expressed and secreted in human preadipocytes from omental fat compared with subcutaneous fat, despite the variability in donor characteristics. Thus, PAPPA expression in preadipocytes may be an intrinsic property of the fat depots and may play a role in depot-specific adipogenesis (Tchkonia et al. 2002).

\section{Proinflammatory cytokines IL1 $\beta$ and TNF $\alpha$ are potent stimulators of PAPPA expression in human preadipocytes}

The proinflammatory state associated with visceral obesity is thought to be a contributing factor to adverse metabolic profiles (Shah et al. 2008). The stromal vascular fraction of adipose tissue contains many cell types including macrophages, lymphocytes, and preadipocytes. Activated macrophages secrete cytokines that can have paracrine effects in adipose tissue (Tchkonia et al. 2013). Omental adipose tissue has been shown to have elevated macrophage infiltration compared with subcutaneous fat, even in lean subjects (Harman-Boehm et al. 2007).

Upregulation of PAPPA mRNA and protein expression in preadipocytes was stimulated by cytokines known to be secreted by activated macrophages. (It should be noted that these cultures are essentially pure preadipocytes (Tchkonia et al. 2002, 2007).) IL1 $\beta$ and TNF $\alpha$ stimulated a threefold increase in PAPPA expression in preadipocytes from the omental and mesenteric depots. Cytokineinduced PAPPA expression is not unique to preadipocytes. Cytokines have also upregulated the expression of PAPPA in human coronary artery smooth muscle cells (Conover et al. 2006), fibroblasts (Resch et al. 2006), and osteoblasts (Conover et al. 2004). Previous experiments in human coronary artery smooth muscle cells indicate that the effects of IL1 $\beta$ and TNF $\alpha$ on PAPPA gene expression are at the level of transcription (Conover et al. 2008). PAPPA expression in human preadipocytes was not stimulated by IL6. There appears to be cell-specific regulation of PAPPA expression by IL6. PAPPA expression was upregulated by IL6 in vascular smooth muscle cells (Boldt \& Conover 2007), but not in vascular endothelial cells or osteoblasts (Conover et al. 2004, 2008). This is not due to the lack of receptor activation, as the IL6 soluble receptor was added. IL6 exhibits both pro- and anti-inflammatory properties.

To determine the intracellular signaling pathways mediating cytokine-induced PAPPA expression, we focused on pathways that are commonly stimulated by cytokines in other cell types (Landry \& Huot 1995, Waskiewicz \& Cooper 1995, Duronio et al. 1998, Young 1998, Li \& Karin 1999, Schaeffer \& Weber 1999). PAPPA upregulation was mediated through pathways typically associated with stress, including the NFאB, p38, and JNK pathways. TNF $\alpha$ was not as effective as IL1 $\beta$ in stimulating the JNK pathway, suggesting differing effects of these cytokines in adipose tissue. However, our data using pathway inhibitors (BAY11-7082, SB203580, and SP600125) do not rule out interactive pathways, as there are issues with specificity (Bain et al. 2007). It is known that the NFкB pathway is not activated in isolation during a stress response, and activation of the p38 and JNK pathways may occur simultaneously (Herlaar \& Brown 1999).

\section{Resveratrol potently inhibits PAPPA expression in human preadipocytes, independent of its known effects on SIRT1 and AMPK activation}

Resveratrol is associated with positive metabolic effects through modulation of cell signaling pathways and has been shown to inhibit PAPPA expression in vascular smooth muscle cells (Conover et al. 2006). Many of the beneficial effects of resveratrol are thought to occur through activation of SIRT1 and/or AMPK. Activation of

Published by Bioscientifica Ltd. 
these pathways has been shown to protect mice against diet-induced obesity and insulin resistance leading to clinical interest in specific SIRT1 analogs (Lagouge et al. 2006). However, not all data convincingly show that action of resveratrol occurs through the sirtuins alone (Baur et al. 2012). Based on our studies using SIRT1 inhibitors, downregulation of PAPPA expression by resveratrol does not seem to be mediated through the activation of SIRT1. Metabolic benefits of resveratrol may also depend on the activation of alternative pathways, as mice with tamoxifen-induced deletion of Sirt1 still show a beneficial glucose response to resveratrol (Price et al. 2012). Another target of resveratrol is to inhibit the c-AMP-specific phosphodiesterases. Rolipram, a phosphodiesterase inhibitor that leads to activation of AMPK and SIRT1, is thought to mimic resveratrol in that it can reproduce its favorable metabolic effects in mice (Park et al. 2012). In our studies, rolipram did not mimic the effect of resveratrol on PAPPA. Thus, resveratrol not only downregulates PAPPA expression in human preadipocytes under basal conditions, but it is also able to overcome upregulation of PAPPA induced by cytokines IL1 $\beta$ and TNF $\alpha$. The effect of resveratrol to inhibit TNF $\alpha$ - or IL1 $\beta$ induced PAPPA expression is unlikely to explain the effect on basal PAPPA expression, as there was no detectable TNF $\alpha$ or IL1 $\beta$ in the media under these conditions. This striking effect of resveratrol on PAPPA expression suggests that downregulation of PAPPA may be an additional mechanism by which resveratrol exerts its beneficial effects on metabolic profiles. The mechanism behind the ability of resveratrol to downregulate PAPPA remains to be elucidated, but possibilities include inhibition of $\mathrm{NF \kappa B}$ activation and attenuation of cell senescence (Holmes-McNary \& Baldsin 2000).

\section{Possible role of PAPPA in depot-specific adipogenesis}

PAPPA proteolyzes inhibitory binding proteins, particularly IGFBP4 (see Fig.7), allowing increased pericellular IGF availability for activation of the IGF receptor (Boldt \& Conover 2007). Therefore, we would expect upregulation of PAPPA to increase local IGF-stimulated differentiation, proliferation, and survival. However, preadipocytes from human omental fat have increased PAPPA but are relatively IGF resistant in terms of proliferation and differentiation (Caserta et al. 2001). Our study did not address the specific role of preadipocyte-derived PAPPA in adipogenesis. However, we speculate that PAPPA is secreted by the preadipocytes or endothelial cells in the stromal vascular fraction (PAPPA is not secreted by macrophages (Conover et al. 2007)) with subsequent paracrine effects on stromal vascular cells as well as mature adipocytes. This is similar to a model proposed for PAPPA in atherosclerotic plaque progression (Conover 2010). A recent study on mice has suggested a novel interactive in vivo setting, whereby PAPPA regulates visceral adipose tissue response to insulin (Conover et al. 2013).

\section{Conclusion}

PAPPA is highly expressed in preadipocytes from omental fat depots. PAPPA expression in human preadipocytes is upregulated by proinflammatory cytokines, particularly IL1 $\beta$ and TNF $\alpha$. This upregulation is mediated through pathways commonly associated with stress, including the JNK, p38, and NFאB pathways. PAPPA mRNA and protein expression is downregulated by resveratrol that has protective metabolic effects. This downregulation by resveratrol appears to be independent of SIRT1 and AMPK. Thus, reduction in PAPPA expression may be another mechanism responsible for the beneficial effects of resveratrol. Further evaluation of the specific role of PAPPA in depot-specific adipogenesis is needed, as these findings in human preadipocytes in conjunction with the work on mice (Conover et al. 2013) suggest the potential for PAPPA to be a therapeutic target in the treatment of visceral obesity.

\section{Declaration of interest}

The authors declare that there is no conflict of interest that could be perceived as prejudicing the impartiality of the research reported.

\section{Funding}

This work was supported by the NIH grant AG028141 (to C A C) and the Minnesota Obesity Center Grant DK50456.

\section{Author contribution statement}

C D-P: designed and performed the experiments, analyzed the data, and wrote the manuscript. C J E: contributed to the immunoblotting experiments. C A C: helped with the design of the experiments, discussed the data, and reviewed the manuscript.

\section{Acknowledgements}

The authors thank Dr James Kirkland and Nino Giorgadze for providing the human preadipocyte cultures and $\mathrm{Dr}$ Michael Jensen for providing the human fat samples. All samples were collected under IRB-approved protocols.

Published by Bioscientifica Ltd. 


\section{References}

Bain J, Plater L, Elliot M, Shpiro N, Hastie CJ, McLauchlan H, Klevernic I, Arthur JSC, Alessi DR \& Cohen P 2007 The selectivity of protein kinase inhibitors: a further update. Biochemical Journal 408 297-315. (doi:10.1042/BJ20070797)

Baur JA, Ungvari Z, Minor RK, Le Couteur DG \& de Cabo R 2012 Are sirtuins viable targets for improving healthspan and lifespan? Nature Reviews. Drug Discovery 11 443-461. (doi:10.1038/nrd3738)

Boldt HB \& Conover CA 2007 Pregnancy-associated plasma protein-A (PAPP-A): a local regulator of IGF bioavailability through cleavage of IGFBPs. Growth Hormone \& IGF Research 17 10-18. (doi:10.1016/ j.ghir.2006.11.003)

Boldt HB \& Conover CA 2011 Overexpression of pregnancy-associated plasma protein-A in ovarian cancer cells promotes tumor growth in vivo. Endocrinology 152 1470-1478. (doi:10.1210/en.20101095)

Boldt HB, Bale LK, Resch ZT, Oxvig C, Overgaard MT \& Conover CA 2013 Effects of mutated pregnancy-associated plasma protein-A on atherosclerotic lesion development in mice. Endocrinology 154 246-252. (doi:10.1210/en.2012-1552)

Caserta F, Tchkonia T, Civelek VN, Prentki M, Brown NF, McGarry JD, Forse RA, Corkey BE, Hamilton JA \& Kirkland JL 2001 Fat depot origin affects fatty acid handling in cultured rat and human preadipocytes. American Journal of Physiology. Endocrinology and Metabolism 280 E238-E247.

Conover CA 2010 PAPP-A: a new anti-aging target? Aging Cell 9 942-946. (doi:10.1111/j.1474-9726.2010.00630.x)

Conover CA 2012 Key questions and answers about pregnancy-associated plasma protein-A. Trends in Endocrinology and Metabolism 23 242-249. (doi:10.1016/j.tem.2012.02.008)

Conover CA, Chen B-K \& Resch ZT 2004 Regulation of pregnancyassociated plasma protein-A expression in cultured human osteoblasts. Bone 34 297-302. (doi:10.1016/j.bone.2003.10.011)

Conover CA, Bale LK, Harrington SC, Resch ZT, Overgaard MT \& Oxvig C 2006 Cytokine stimulation of pregnancy-associated plasma protein A expression in human coronary artery smooth muscle cells: inhibition by resveratrol. American Journal of Physiology. Cell Physiology 290 C183-C188. (doi:10.1152/ajpcell.00199.2005)

Conover CA, Harrington SC, Bale LK \& Oxvig C 2007 Surface association of pregnancy associated plasma protein-A accounts for its co-localization with activated macrophages. American Journal of Physiology. Heart and Circulatory Physiology 292 H994-H1000. (doi:10.1152/ajpheart.00798. 2006)

Conover CA, Harrington SC \& Bale LK 2008 Differential regulation of pregnancy associated plasma protein-A in human coronary artery endothelial cells and smooth muscle cells. Growth Hormone \& IGF Research 18 213-220. (doi:10.1016/j.ghir.2007.09.001)

Conover CA, Bale LK, Mader JR, Mason MA, Keenan KP \& Marler RJ 2010 Longevity and age-related pathology of mice deficient in pregnancy-associated plasma protein-A. Journals of Gerontology. Series A, Biological Sciences and Medical Sciences 65 590-599. (doi:10.1093/ gerona/glq032)

Conover CA, Harstad SL, Tchkonia T \& Kirkland JL 2013 Preferential impact of pregnancy associated plasma protein-A deficiency on visceral fat in mice on high fat diet. American Journal of Physiology. Endocrinology and Metabolism 305 E1145-E1153. (doi:10.1152/ajpendo. 00405.2013)

Coppack SW 2001 Pro-inflammatory cytokines and adipose tissue. Proceedings of the Nutrition Society $60349-356$. (doi:10.1079/ PNS2001110)

Duronio V, Scheid MP \& Ettinger S 1998 Downstream signalling events regulated by phosphatidylinositol 3-kinase activity. Cellular Signalling 10 233-239. (doi:10.1016/S0898-6568(97)00129-0)
Franchimont N, Gangji V, Durant D \& Canalis E 1997 Interleukin-6 with its soluble receptor enhances the expression of insulin-like growth factor-I in osteoblasts. Endocrinology 138 5248-5255.

Harman-Boehm I, Bluher M, Redel H, Sion-Vardy N, Ovadia S, Avinoach E, Shai I, Kloting N, Stumvoll M, Bashan N et al. 2007 Macrophage infiltration into omental versus subcutaneous fat across different populations: effect of regional adiposity and the comorbidities of obesity. Journal of Clinical Endocrinology and Metabolism 92 2240-2247. (doi:10.1210/jc.2006-1811)

Harrington SC, Simari RD \& Conover CA 2007 Genetic deletion of pregnancy-associated plasma protein-A is associated with resistance to atherosclerotic lesion development in apolipoprotein E-deficient mice challenged with a high-fat diet. Circulation Research 100 1696-1702. (doi:10.1161/CIRCRESAHA.106.146183)

Herlaar E \& Brown Z 1999 p38 MAPK signalling cascades in inflammatory disease. Molecular Medicine Today 5 439-447. (doi:10.1016/S13574310(99)01544-0)

Holmes-McNary M \& Baldsin AS Jr 2000 Chemopreventive properties of trans-resveratrol are associated with inhibition of activation of the IкB kinase. Cancer Research 60 3477-3483.

Howitz KT, Bitterman KJ, Cohen HY, Lamming DW, Lavu S, Wood JG, Zipkin RE, Chung P, Kisielewski A, Zhang LL et al. 2003 Small molecule activators of sirtuins extend Saccharomyces cerevisiae lifespan. Nature 425 191-196. (doi:10.1038/nature01960)

Lacasa D, Taleb S, Keophiphath M, Miranville A \& Clement K 2007 Macrophage-secreted factors impair human adipogenesis: involvement of proinflammatory state in preadipocytes. Endocrinology 148 868-877. (doi:10.1210/en.2006-0687)

Lagouge M, Argmann C, Gerhart-Hines Z, Meziane H, Lerin C, Daussin F, Messadeq N, Milne J, Lambert P, Elliott P et al. 2006 Resveratrol improves mitochondrial function and protects against metabolic disease by activating SIRT1 and PGC-1 $\alpha$. Cell 127 1109-1122. (doi:10.1016/j.cell.2006.11.013)

Landry J \& Huot J 1995 Modulation of actin dynamics during stress and physiological stimulation by a signaling pathway involving p38 MAP kinase and heat-shock protein 27. Biochemistry and Cell Biology $\mathbf{7 3}$ 703-707. (doi:10.1139/095-078)

Li N \& Karin M 1999 Is NF- $\mathrm{kB}$ the sensor of oxidative stress? FASEB Journal 13 1137-1143.

Park SJ, Ahmad F, Philp A, Baar K, Williams T, Luo H, Ke H, Rehmann H, Taussig R, Brown AL et al. 2012 Resveratrol ameliorates aging-related metabolic phenotypes by inhibiting cAMP phosphodiesterases. Cell 148 421-433. (doi:10.1016/j.cell.2012.01.017)

Price NL, Gomes AP, Ling AJ, Duarte FV, Martin-Montalvo A, North BJ, Agarwal B, Ye L, Ramadori G, Teodoro JS et al. 2012 SIRT1 is required for AMPK activation and the beneficial effects of resveratrol on mitochondrial function. Cell Metabolism 15 675-690. (doi:10.1016/ j.cmet.2012.04.003)

Resch ZT, Oxvig C, Bale LK \& Conover CA 2006 Stress-activated signaling pathways mediate the stimulation of pregnancy-associated plasma protein-A expression in cultured human fibroblasts. Endocrinology 147 885-890. (doi:10.1210/en.2005-0908)

Schaeffer HJ \& Weber MJ 1999 Mitogen-activated protein kinases: specific messages from ubiquitous messengers. Molecular and Cellular Biology 19 2435-2444.

Shah A, Mehta N \& Reilly MP 2008 Adipose inflammation, insulin resistance, and cardiovascular disease. Journal of Parenteral and Enteral Nutrition 32 638-644. (doi:10.1177/0148607108325251)

Tchkonia T, Giorgadze N, Pirtskhalava T, Karagiannides I, Forse RA, Deponte M, Stevenson M, Guo W, Han J, Waloga G et al. 2002 Fat depot origin affects adipogenesis in primary cultured and cloned human preadipocytes. American Journal of Physiology. Regulatory, Integrative and Comparative Physiology 282 R1286-R1296.

Tchkonia T, Lenburg M, Thomou T, Giorgadze N, Frampton G, Pirtskhalava T, Cartwright A, Cartwright M, Flanagan J, Karagiannides I et al. 2007 Identification of depot-specific human fat cell progenitors 
through distinct expression profiles and developmental gene patterns. American Journal of Physiology. Endocrinology and Metabolism 292 E298-E307. (doi:10.1152/ajpendo.00202.2006)

Tchkonia T, Morbeck DE, Von Zglinicki T, Van Deursen J, Lustgarten J, Scrable H, Khosla S, Jensen MD \& Kirkland JL 2010 Fat tissue, aging, and cellular senescence. Aging Cell 9 667-684. (doi:10.1111/j.1474-9726. 2010.00608.x)

Tchkonia T, Thomou T, Zhu Y, Karagiannides I, Pothoulakis C, Jensen MD \& Kirkland JL 2013 Mechanisms and metabolic implications of regional differences among fat depots. Cell Metabolism 17 644-656. (doi:10.1016/j.cmet.2013.03.008)
Waskiewicz AJ \& Cooper JA 1995 Mitogen and stress response pathways: MAP kinase cascades and phosphatase regulation in mammals and yeast. Current Opinion in Cell Biology 7 798-805. (doi:10.1016/09550674(95)80063-8)

Wood JG, Rogina B, Lavu S, Howitz K, Helfand SL, Tatar M \& Sinclair D 2004 Sirtuin activators mimic caloric restriction and delay ageing in metazoans. Nature 430 686-689. (doi:10.1038/ nature02789)

Young PR 1998 Pharmacological modulation of cytokine action and production through signaling pathways. Cytokine \& Growth Factor Reviews 9 239-257. (doi:10.1016/S1359-6101(98)00011-2)

Received in final form 14 April 2014

Accepted 22 April 2014

Accepted Preprint published online 29 April 2014
Published by Bioscientifica Ltd. 